\title{
Cytoreductive Surgery and Hyperthermic Intraperitoneal Chemotherapy in Elderly Patients: Complete Cytoreduction Is Feasible and Crucial for Improved Survival Despite High Carcinomatosis Index
}

\author{
SAMER A. NAFFOUJE ${ }^{1}$ and GEORGE I. SALTI ${ }^{2,3}$ \\ ${ }^{1}$ Department of General Surgery, and ${ }^{3}$ Division of Surgical Oncology, \\ University of Illinois at Chicago Hospital and Health Sciences System, Chicago, IL, U.S.A.; \\ ${ }^{2}$ Department of Surgical Oncology, Edward Cancer Center, Naperville, IL, U.S.A.
}

\begin{abstract}
Background: We aimed to study the surgical outcomes of cytoreductive surgery (CRS) and hyperthermic intraperitoneal chemotherapy (HIPEC) in elderly patients, and investigate whether the pursuit of complete cytoreduction implies a survival benefit despite a high peritoneal carcinomatosis index (PCI). Patients and Methods: All CRS and HIPEC procedures performed for patients with peritoneal surface malignancy $(P S M) \geq 65$ years old between 2005-2017 were included. A control group comprising patients 60-64 years old who underwent CRS and HIPEC over the same period was also selected for comparison of characteristics and outcomes. Results: A total of 54 elderly patients and 27 control patients were included. Increasing age did not result in any difference in demographics, perioperative characteristics, or surgical outcomes. Elderly patients who achieved completeness of cytoreduction (CC) 0/1 were compared to those with $\mathrm{CC} 2 / 3$, and were found to have a higher body mass index, lower peritoneal cancer index, higher rate of inpatient mortality, and a significantly longer median survival (43 vs. 15 months; $p=0.020$ ). Cox multivariate regression identified Charlson score $\geq 2$, the occurrence of major morbidities, colorectal and sarcoma primary tumor, and $C C 2 / 3$ as significant predictors of poor survival. Conclusion: CRS and HIPEC are feasible in elderly patients without a significant effect of increasing age on the surgical outcomes. CCO/1 carries higher postoperative mortality rate, but yields a longer overall survival. Baseline comorbidities, postoperative
\end{abstract}

Correspondence to: Samer A. Naffouje, MD, University of Illinois at Chicago Health and Sciences System, $840 \mathrm{~S}$ Wood Street, Suite 376 CSN, Chicago, IL 60612, U.S.A. Tel: +1 3129966765, e-mail: snaffouj@uic.edu

Key Words: Cytoreductive surgery, CRS, HIPEC, elderly, survival. complications, certain histologies, and $C C 2 / 3$ are predictors of poor prognosis in this population. PCI is a predictor of CC, but not of survival when CCO/1 is achieved.

Cytoreductive surgery (CRS) and hyperthermic intraperitoneal chemotherapy (HIPEC), as an aggressive surgical procedure, has resulted in improved survival rates in select patients diagnosed with peritoneal surface malignancy (PSM) over the past two decades. The survival benefit of CRS and HIPEC was most conspicuous in pseudomyxoma peritonei (PMP) where 20 -year survival was as high as $70 \%$ when certain conditions were met (1). However, CRS and HIPEC have been associated with increased morbidity and mortality rates of $24 \%(0-52 \%)$ and $3 \%(0-18 \%)$, respectively (2-5). Because of the high risk of this procedure, a question has been raised about the benefit it would offer to patients of old age with PSM.

The World Health Organization adopted the chronological age of 65 years the definition of 'old' in developed countries, even though the United Nations accepted $60+$ years as the cut-off worldwide (6). Interestingly, this number is set to correlate with the age of retirement and receiving a pension, thus the definition is arbitrary and no consensus has been reached about the age at which a person becomes 'old'.

Owing to the improved healthcare, life expectancy in the United States has reached 78 years for males, and 82 years for females. The elderly group will continue to grow in number and approach one-third of the population in the United States by 2050 (7). Consequently, the scenario of PSM in elderly patients is expected to be faced more frequently in the upcoming years, hence the importance of determining a reasonable and beneficial management for this scenario.

In general, elderly patients with cancer diagnosis, especially in the presence of disseminated disease, are approached with caution with a tendency toward nonoperative management. This is mainly due to the concern of 
Table I. Comparison of demographic and perioperative characteristics between the control group (60-64 years old) and comparable age increments of the elderly study population.

\begin{tabular}{|c|c|c|c|c|c|}
\hline \multirow[b]{2}{*}{$\begin{array}{c}\text { Characteristic } \\
(\mathrm{N}=27)\end{array}$} & \multicolumn{4}{|c|}{ Age group, years } & \multirow[b]{2}{*}{$p$-Value } \\
\hline & $\begin{array}{l}60-64 \\
(\mathrm{~N}=24)\end{array}$ & $\begin{array}{c}65-69 \\
(\mathrm{~N}=19)\end{array}$ & $\begin{array}{c}70-74 \\
(\mathrm{~N}=11)\end{array}$ & $75+$ & \\
\hline \multicolumn{6}{|l|}{ Gender } \\
\hline Male & $11(39.3 \%)$ & $8(33.3 \%)$ & $10(52.6 \%)$ & $6(54.5 \%)$ & \multirow{2}{*}{0.495} \\
\hline Female & $17(60.7 \%)$ & $16(66.7 \%)$ & $9(47.4 \%)$ & $5(45.5 \%)$ & \\
\hline \multicolumn{6}{|l|}{$\mathrm{BMI}, \mathrm{kg} / \mathrm{m}^{2}$} \\
\hline Mean \pm SD & $25.76 \pm 6.34$ & $25.82 \pm 5.77$ & $27.17 \pm 5.23$ & $26.07 \pm 5.72$ & 0.820 \\
\hline \multicolumn{6}{|l|}{ Charlson Comorbidity Index } \\
\hline 0 & $10(35.7 \%)$ & $8(33.3 \%)$ & $3(15.8 \%)$ & $4(36.4 \%)$ & \multirow{3}{*}{0.596} \\
\hline 1 & $12(42.9 \%)$ & $8(33.3 \%)$ & $7(36.8 \%)$ & $4(36.4 \%)$ & \\
\hline$\geq 2$ & $6(21.4 \%)$ & $8(33.3 \%)$ & $9(47.4 \%)$ & $3(27.3 \%)$ & \\
\hline \multicolumn{6}{|l|}{ 30-Day morbidity/mortality } \\
\hline None (Clavien 0) & $18(64.3 \%)$ & $12(50.0 \%)$ & $13(68.5 \%)$ & $7(63.3 \%)$ & \multirow{4}{*}{0.150} \\
\hline Minor (Clavien 1-2) & $7(25.0 \%)$ & $10(41.7 \%)$ & $2(10.5 \%)$ & $1(9.1 \%)$ & \\
\hline Major (Clavien 3-4) & $3(10.7 \%)$ & $1(4.2 \%)$ & $2(10.5 \%)$ & $3(27.3 \%)$ & \\
\hline Mortality (Clavien 5) & $0(0.0 \%)$ & $1(4.2 \%)$ & $2(10.5 \%)$ & $0(0.0 \%)$ & \\
\hline \multicolumn{6}{|l|}{ Site of primary cancer } \\
\hline Appendix & $9(32.1 \%)$ & $1(4.2 \%)$ & $1(5.3 \%)$ & $0(0.0 \%)$ & \multirow{9}{*}{0.328} \\
\hline Colon & $4(14.3 \%)$ & $5(20.8 \%)$ & $7(36.8 \%)$ & $4(36.4 \%)$ & \\
\hline Endometrial & $1(3.6 \%)$ & $0(0.0 \%)$ & $0(0.0 \%)$ & $0(0.0 \%)$ & \\
\hline Gastric & $1(3.6 \%)$ & $2(8.3 \%)$ & $0(0.0 \%)$ & $0(0.0 \%)$ & \\
\hline Liver & $0(0.0 \%)$ & $1(4.2 \%)$ & $1(5.3 \%)$ & $0(0.0 \%)$ & \\
\hline Mesothelioma & $0(0.0 \%)$ & $2(8.3 \%)$ & $1(5.3 \%)$ & $1(9.1 \%)$ & \\
\hline Ovary & $5(17.9 \%)$ & $4(16.7 \%)$ & $1(5.3 \%)$ & $2(18.2 \%)$ & \\
\hline PMP & $7(25.0 \%)$ & $7(29.2 \%)$ & $7(36.8 \%)$ & $4(36.4 \%)$ & \\
\hline Sarcoma & $1(3.6 \%)$ & $2(8.3 \%)$ & $1(5.3 \%)$ & $0(0.0 \%)$ & \\
\hline \multicolumn{6}{|l|}{ Length of stay, days } \\
\hline Mean \pm SD & $11.17 \pm 6.37$ & $11.25 \pm 4.58$ & $9.73 \pm 5.93$ & $13.09 \pm 8.47$ & \multirow[t]{2}{*}{0.551} \\
\hline Median & 9 & 10.5 & 8 & 10 & \\
\hline \multicolumn{6}{|l|}{ PCI } \\
\hline Mean \pm SD & $13.07 \pm 10.51$ & $14.91 \pm 9.62$ & $13.84 \pm 9.19$ & $15.63 \pm 9.34$ & \multirow[t]{2}{*}{0.860} \\
\hline Median & 11 & 14 & 13 & 14 & \\
\hline \multicolumn{6}{|l|}{ Length of operation, minutes } \\
\hline Mean \pm SD & $390 \pm 128$ & $439 \pm 114$ & $379 \pm 127$ & $360 \pm 83$ & \multirow[t]{2}{*}{0.330} \\
\hline Median & 372 & 412 & 352 & 332 & \\
\hline \multicolumn{6}{|l|}{ Estimated blood loss, ml } \\
\hline Mean \pm SD & $343 \pm 297$ & $535 \pm 455$ & $469 \pm 419$ & $427 \pm 320$ & \\
\hline Median & 300 & 400 & 300 & 250 & 0.216 \\
\hline Median no. of visceral resections & 5 & 6 & 5 & 4 & 0.548 \\
\hline \multicolumn{6}{|l|}{$\mathrm{CC}$} \\
\hline $\mathrm{CC} 0 / 1$ & $25(89.3 \%)$ & $19(79.2 \%)$ & $16(84.2 \%)$ & $7(63.6 \%)$ & \multirow[t]{2}{*}{0.300} \\
\hline $\mathrm{CC} 2 / 3$ & $3(10.7 \%)$ & $5(20.8 \%)$ & $3(15.8 \%)$ & $4(36.4 \%)$ & \\
\hline
\end{tabular}

BMI: Body mass index; CC: completeness of cytoreduction; PCI: peritoneal carcinomatosis index.

high postoperative morbidity and mortality rates associated with CRS and HIPEC which are thought to worsen with advancing age. In parallel experiences, age was found to be a significant risk factor for increased morbidity and mortality in major gastrointestinal surgeries (8).

Herein, we analyzed the surgical outcomes of CRS and HIPEC in our elderly patients, and aimed to answer three questions: i) Does increasing age affect the immediate surgical outcomes of CRS and HIPEC? ii) Does complete cytoreduction carry any survival benefit for the elderly population? and iii) What are the factors that predict poor survival in the elderly following CRS and HIPEC?

\section{Patients and Methods}

All CRS and HIPEC procedures which were performed for patients $\geq 65$ years old with PSM between 2005-2017 were included. We also evaluated all patients between the ages 60-64 who underwent CRS and 
HIPEC during the same period as a control group for comparison. We chose these patients as controls rather than performing the analysis on all younger patients because they belong to the immediately younger age group, thus they typically have similar comorbidities and closely resemble the older group. For comparative purposes, the patients were divided into age groups of 5-year increments.

Chi-square, Student's $t$-test, and Mann-Whitney $U$-test were used for the comparison of the characteristics and outcomes of the two groups. Completeness of cytoreduction (CC) score was reported as $\mathrm{CC} 0$ for no residual disease, $\mathrm{CC} 1$ for macroscopic residual disease $<0.25 \mathrm{~cm}, \mathrm{CC} 2$ for macroscopic residual disease $0.25-2.5 \mathrm{~cm}$, and $\mathrm{CC} 3$ for gross residual disease $(>2.5 \mathrm{~cm})$. Intraoperative peritoneal cancer index (PCI) was documented per the 13-region and lesion size scoring system (9). Kaplan-Meier method was used to create the survival curve for the elderly patients based on the status of CC $(\mathrm{CC} 0 / 1$ vs. CC2/3). Log-rank test was utilized to compare the median survival of the two groups. Cox univariate and multivariate regressions were applied to identify the significant predictors of survival following CRS and HIPEC. Significance was set at $p<0.05$ throughout the analysis.

\section{Results}

Eighty patients who underwent $81 \mathrm{CRS}$ and HIPEC were evaluated: 54 belonged to the elderly group ( $\geq 65$ years old) and 27 to the control group (60-64 years old). The mean age in the elderly group was $70.7 \pm 4.1$ (median 70 years, range $=65-80$ years). Initially, the patients were divided into groups of 5-year increments to study the impact of increasing age on the surgical outcomes. No significant differences were noted between the aging groups in regards to sex, body mass index (BMI), Charlson morbidity score, length of surgery, estimated blood loss, postoperative morbidity and mortality, length of stay, PCI score, number of visceral resections, and completion of cytoreduction. The results of the comparative analysis between the control and the elderly age groups is summarized in Table I.

The elderly population was then divided based on the $\mathrm{CC}$ score into $\mathrm{CC} 0 / 1(\mathrm{n}=42)$ and $\mathrm{CC} 2 / 3(\mathrm{n}=12)$ groups. $\mathrm{CC} 0 / 1$ patients had a significantly higher BMI $(p=0.023)$, lower PCI $(p=0.002)$, and 30-day mortality ( $p=0.021)$. Comparison of the $\mathrm{CC} 0 / 1$ and $\mathrm{CC} 2 / 3$ groups is shown in Table II.

Kaplan-Meier analysis demonstrated significantly longer overall survival in the $\mathrm{CC} 0 / 1$ group compared to the $\mathrm{CC} 2 / 3$ group $(p=0.020)$. Survival curves are demonstrated in Figure 1A. Subgroup analysis of elderly patients with extensive PCI defined as $\geq 16(10$. 11$)$ showed that $\mathrm{CC} 0 / 1$ continued to provide improved survival compared to $\mathrm{CC} 2 / 3$ as shown in Figure 1B.

Univariate and multivariate Cox regressions were conducted to identify the factors that significantly contributed to the patients' survival. The univariate analysis identified Charlson score $\geq 2$, occurrence of major postoperative morbidities (Clavien grade III-IV), colorectal and sarcoma primaries (in comparison to PMP, the referent histology), PCI, and CC2/3 as predictors of poor survival. When the factors were tested in the multivariate regression,
Table II. Comparison of demographic and perioperative characteristics between elderly patients with completeness of cytoreduction (CC) score of $C C O / 1$ vs. CC2/3.

\begin{tabular}{|c|c|c|c|}
\hline Characteristic & $\begin{array}{l}\mathrm{CC} 0 / 1 \\
(\mathrm{~N}=42)\end{array}$ & $\begin{array}{l}\mathrm{CC} 2 / 3 \\
(\mathrm{~N}=12)\end{array}$ & $p$-Value \\
\hline \multicolumn{4}{|l|}{ Gender } \\
\hline Male & $20(47.6 \%)$ & $4(33.3 \%)$ & \multirow[t]{2}{*}{0.294} \\
\hline Female & $22(52.4 \%)$ & $8(66.7 \%)$ & \\
\hline \multicolumn{4}{|l|}{$\mathrm{BMI}, \mathrm{kg} / \mathrm{m}^{2}$} \\
\hline Mean \pm SD & $27.12 \pm 5.33$ & $23.12 \pm 4.7$ & 0.023 \\
\hline \multicolumn{4}{|l|}{ Age, years } \\
\hline Mean \pm SD & $70.52 \pm 4.08$ & $71.33 \pm 4.4$ & \multirow[t]{2}{*}{0.580} \\
\hline Median (range) & 70 & 70 & \\
\hline \multicolumn{4}{|c|}{ Charlson Comorbidity Index } \\
\hline 0 & $12(28.6 \%)$ & $3(25.0 \%)$ & \multirow{3}{*}{0.868} \\
\hline 1 & $14(33.3 \%)$ & $5(41.7 \%)$ & \\
\hline$\geq 2$ & $16(38.1 \%)$ & $4(33.3 \%)$ & \\
\hline \multicolumn{4}{|c|}{ 30-Day morbidity and mortality } \\
\hline None (Clavien 0) & $26(61.9 \%)$ & $6(50.0 \%)$ & \multirow{4}{*}{0.021} \\
\hline Minor (Clavien 1-2) & $8(19.1 \%)$ & $5(41.6 \%)$ & \\
\hline Major (Clavien 3-4) & $5(11.9 \%)$ & $1(8.4 \%)$ & \\
\hline Mortality (Clavien 5) & $3(7.1 \%)$ & $0(0.0 \%)$ & \\
\hline \multicolumn{4}{|l|}{ Site of primary cancer } \\
\hline Appendix & $1(2.4 \%)$ & $1(8.3 \%)$ & \multirow{8}{*}{0.691} \\
\hline Colon & $13(31.0 \%)$ & $3(25.0 \%)$ & \\
\hline Gastric & $2(4.8 \%)$ & $0(0.0 \%)$ & \\
\hline Liver & $2(4.8 \%)$ & $0(0.0 \%)$ & \\
\hline Mesothelioma & $3(7.1 \%)$ & $1(8.3 \%)$ & \\
\hline Ovary & $4(9.5 \%)$ & $3(25.0 \%)$ & \\
\hline PMP & $14(33.3 \%)$ & $4(33.3 \%)$ & \\
\hline Sarcoma & $3(7.1 \%)$ & $0(0.0 \%)$ & \\
\hline \multicolumn{4}{|l|}{ Length of stay, days } \\
\hline Mean \pm SD & $10.78 \pm 5.88$ & $12.16 \pm 6.57$ & \multirow[t]{2}{*}{0.521} \\
\hline Median & 9 & 10 & \\
\hline \multicolumn{4}{|l|}{ PCI } \\
\hline Mean \pm SD & $12.31 \pm 7.87$ & $23.00 \pm 9.24$ & \multirow[t]{2}{*}{0.002} \\
\hline Median & 13 & 23 & \\
\hline \multicolumn{4}{|c|}{ Length of operation, minutes } \\
\hline Mean \pm SD & $403 \pm 396$ & $396 \pm 100$ & \multirow[t]{2}{*}{0.844} \\
\hline Median & 400 & 392 & \\
\hline \multicolumn{4}{|l|}{ Estimated blood loss, $\mathrm{ml}$} \\
\hline Mean \pm SD & $516 \pm 441$ & $400 \pm 295$ & \multirow[t]{2}{*}{0.297} \\
\hline Median & 473 & 410 & \\
\hline $\begin{array}{l}\text { Median (range) no. } \\
\text { of visceral resections }\end{array}$ & $5(0-9)$ & $5(0-8)$ & 0.965 \\
\hline
\end{tabular}

BMI: Body mass index; PCI: peritoneal carcinomatosis index.

PCI was rejected from the model whereas the remaining factors continued to demonstrate significance. The results of the univariate and multivariate analyses with the hazard ratios are shown in Table III.

\section{Discussion}

Chronological age has been demonstrated to be a significant risk factor for postoperative morbidity following major non- 
cardiac surgery in general (12), and in CRS and HIPEC in particular $(13,14)$. This is not surprising since most of the studies compared the elderly to the entire patient population, and advanced age is usually accompanied by significant comorbidities and a reduction in the functional status, which are considered major contributors to a poorer surgical outcome.

In this study, we demonstrate that offering CRS and HIPEC to an elderly patient with PSM should not be withheld because of advanced age alone. Increasing age groups follow a comparable postoperative course following this major procedure and resemble each other in their demographic and perioperative characteristics.

Notably, age by itself, as a continuous factor, was not shown to be a significant prognostic factor in our univariate or multivariate regression models. However, having multiple comorbidities at baseline as reported in the Charlson score $(\geq 2)$, occurrence of major postoperative morbidities, macroscopic cytoreduction, and certain histologies (compared to PMP) proved to be significant factors in the prognostic model. While patients' comorbidities and the primary histology are non-modifiable risk factors, avoiding major postoperative complications and achieving $\mathrm{CC} 0 / 1$ perhaps are. Therefore, we stress careful patient selection in this challenging group to minimize postoperative complications which may, in turn, lead to better survival.

We evaluated several factors that may influence overall survival to improve patient selection among the elderly for CRS and HIPEC. BMI demonstrated a trend as a protective factor which, in addition to the comorbidity index, can be used to reflect the patient's performance status. Lower BMI in patients with PSM may indicate a depleted reserve and a poor nutritional status. Unlike increased BMI, low BMI is not studied in the CRS and HIPEC literature as an independent factor. Nonetheless, many studies reported on the influence of malnutrition on postoperative complications in oncologic and non-oncologic surgeries (15-19). The Eastern Cooperative Oncology Group classification, as a standard tool for functional status assessment, was shown to be a significant prognostic factor for postoperative complications in the oncologic elderly population (20). Moreover, a low albumin level is an established parameter of malnutrition that predicts surgical morbidity and mortality in benign or malignant surgical indications $(21,22)$.

Our analysis also suggests that certain primary histologies should be regarded as risk factors for a reduced survival. Most prominently, CRC and sarcoma origins had a 4-fold and 5-fold chance of mortality, respectively, compared to patients with PMP in the multivariate regression model [hazard ratio (HR) $=4.25, p=0.009$ and $\mathrm{HR}=5.66, p=0.030$. respectively]. We expected that gastric primary would demonstrate a similar effect. However, due to the small number of patients in each group, significance was not demonstrated in the same model.
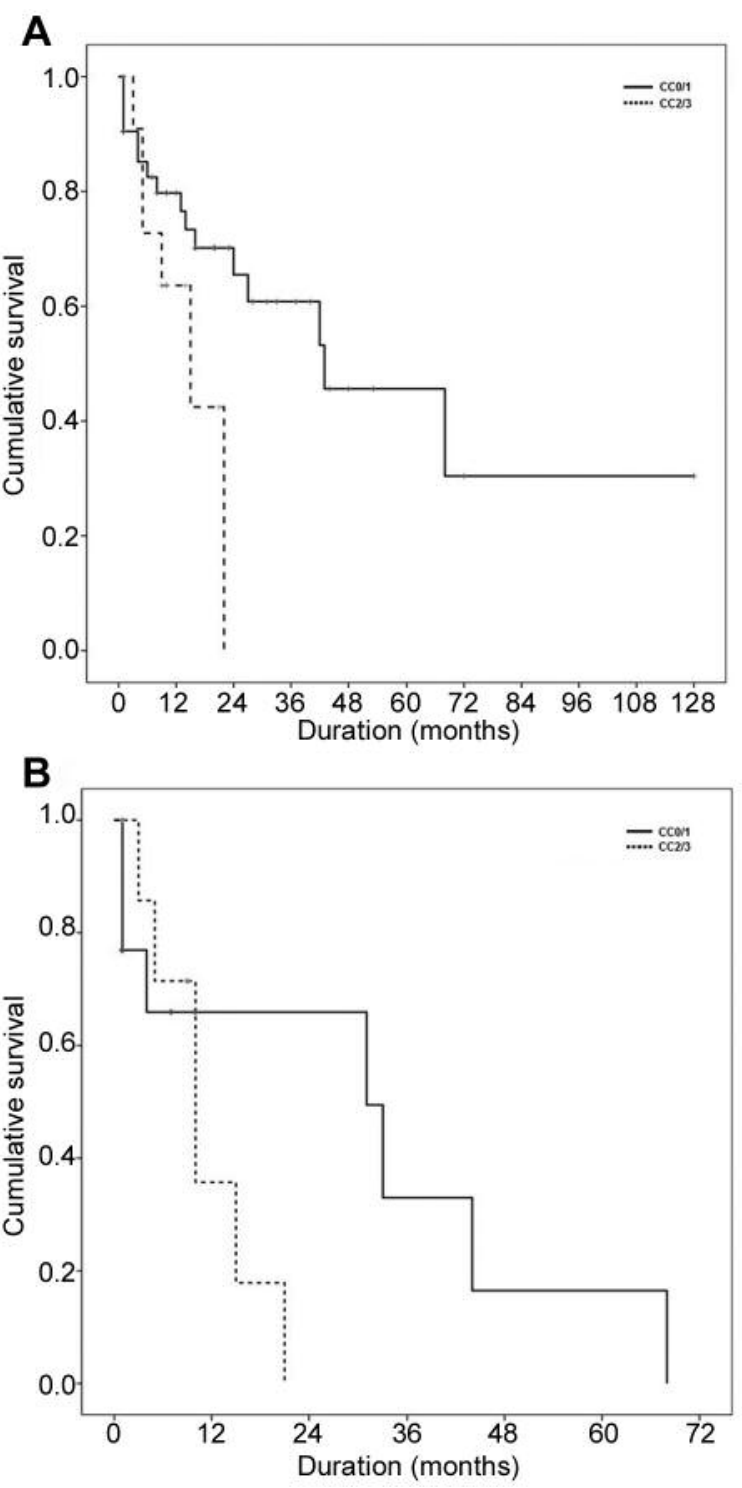

Figure 1. Kaplan-Meier curves for overall survival for elderly patients with completeness of cytoreduction (CC) $0 / 1$ vs. $\quad$ CC2/3 (median $=43.09 \pm 15.5 \mathrm{vs} .15 .00 \pm 5.6$ months; $p=0.020$ ) (A) and those with a high peritoneal carcinomatosis index $(\geq 16), C C 0 / 1 \mathrm{vs} . C C 2 / 3$ (median=31.00 \pm 12.8 vs. 10.00 \pm 2.7 months; $p=0.044)(B)$.

PCI is an important factor in survival prediction in patients who undergo CRS and HIPEC $(23,24)$. Nonetheless, PCI did not function as a significant predictor for overall survival in our population, whereas $\mathrm{CC} 0$ and $\mathrm{CC} 1$ were significantly favorable predictors of longer survival. The subgroup analysis showed that the influence of PCI on survival is less if complete cytoreduction is achieved, even in the presence of extensive peritoneal dissemination $(\mathrm{PCI} \geq 16)$. 
Table III. Univariate and multivariate cox regression analyses to identify significant predictors of survival in our elderly population.

\begin{tabular}{|c|c|c|c|c|}
\hline \multirow[b]{2}{*}{ Factor } & \multicolumn{2}{|c|}{ Univariate analysis } & \multicolumn{2}{|c|}{ Multivariate analysis } \\
\hline & Hazard ratio $(\mathrm{CI})$ & $p$-Value & Hazard ratio $(\mathrm{CI})$ & $p$-Value \\
\hline Age & $0.988(0.963-1.014)$ & 0.369 & $0.982(0.956-1.008)$ & 0.474 \\
\hline \multicolumn{5}{|l|}{ Gender } \\
\hline Male & Referent & & Referent & \\
\hline Female & $0.605(0.338-1.083)$ & 0.090 & $1.160(0.512-2.629)$ & 0.722 \\
\hline BMI & $0.949(0.897-1.003)$ & 0.065 & $0.947(0.889-1.008)$ & 0.087 \\
\hline \multicolumn{5}{|l|}{ Charlson Comorbidity Index } \\
\hline 0 & Referent & & Referent & \\
\hline 1 & $1.498(0.754-2.975)$ & 0.754 & $1.798(0.709-4.561)$ & 0.817 \\
\hline$\geq 2$ & $2.231(1.292-2.563)$ & 0.015 & $1.885(1.182-3.442)$ & 0.039 \\
\hline Major morbidity (III-IV) & $2.017(1.163-4.224)$ & 0.033 & $1.975(1.113-5.109)$ & 0.044 \\
\hline \multicolumn{5}{|l|}{ Primary cancer } \\
\hline PMP & Referent & & Referent & \\
\hline $\mathrm{CRC}$ & $4.729(1.809-12.361)$ & 0.002 & $4.249(1.436-12.575)$ & 0.009 \\
\hline Gastric & $4.392(0.845-22.831)$ & 0.078 & $5.386(0.851-34.079)$ & 0.079 \\
\hline Ovary & $2.340(0.671-8.160)$ & 0.182 & $2.007(0.510-7.897)$ & 0.319 \\
\hline Sarcoma & $4.480(1.173-17.105)$ & 0.028 & $5.662(1.307-24.534)$ & 0.030 \\
\hline Other & $4.260(1.129-16.079)$ & 0.032 & $3.910(0.966-15.823)$ & 0.056 \\
\hline PCI & $1.034(1.003-1.067)$ & 0.033 & $1.024(0.977-1.074)$ & 0.065 \\
\hline \multicolumn{5}{|l|}{$\mathrm{CC}$} \\
\hline $0 / 1$ & Referent & & Referent & \\
\hline $2 / 3$ & $3.013(1.296-8.559)$ & 0.023 & $2.563(1.208-9.867)$ & 0.035 \\
\hline Hepatectomy & $1.388(0.959-2.115)$ & 0.072 & $1.650(0.931-2.498)$ & 0.088 \\
\hline Splenectomy & $0.548(0.311-3.551)$ & 0.298 & $0.286(0.015-5.372)$ & 0.403 \\
\hline
\end{tabular}

BMI: Body mass index; CC: completeness of cytoreduction; CI: 95\% confidence interval; PCI: peritoneal carcinomatosis index.

Table IV. Summary of the studies addressing cytoreductive surgery (CRS) and (HIPEC) in the elderly.

\begin{tabular}{|c|c|c|c|c|c|c|c|c|}
\hline Author (year) (Ref) & $\mathrm{N}$ & $\begin{array}{c}\text { Elderly age } \\
\text { cutoff } \\
\text { (median), years }\end{array}$ & $\begin{array}{c}\text { Control } \\
\text { (age, years) }\end{array}$ & $\begin{array}{c}\text { Median } \\
\text { PCI }\end{array}$ & $\begin{array}{c}\% \\
\mathrm{CC} 0 / 1\end{array}$ & $\begin{array}{c}\% \\
\mathrm{MM}\end{array}$ & $\begin{array}{l}\% \text { Mortality } \\
\text { (days) }\end{array}$ & Predictors (outcome) \\
\hline Muller et al. (2008) (26) & 47 & $\geq 65(71)$ & No & 16 & 84 & 17 & $0(30)$ & SIRS (morbidity and mortality) \\
\hline Macri et al. (2011) (27) & 11 & $\geq 65$ (69) & Yes $(30-63)$ & 9.6 & 100 & 27.3 & $18.2(30)$ & NA \\
\hline Klaver et al. (2012) (28) & 24 & $\geq 70(73)$ & No & 8 & 100 & 34 & $0(30)$ & None \\
\hline Votanopoulos et al. (2013) (22) & 81 & $\geq 70(73)$ & Yes (NR) & $\mathrm{NR}^{*}$ & NR & 38 & $13.6(30)$ & $\begin{array}{c}\mathrm{MM}, \mathrm{CC}, \mathrm{CRC} \text { and gastric, } \\
\text { Albumin, learning curve (survival) }\end{array}$ \\
\hline Tabrizian et al. (2013) (11) & 35 & $\geq 65(70)$ & Yes (mean 51) & 15.3 & 80 & 19.4 & $19.4(90)$ & NA \\
\hline Spiliotis et al. (2014) (29) & 3 & $\geq 70(74.5)$ & Yes (NR) & 25 & 77 & NR & $3.3(30)$ & NA \\
\hline Cascales-Campos et al. (2014) (30) & 9 & $\geq 75(\mathrm{NR})$ & Yes (NR) & 10.3 & 100 & 56 & $0(30)$ & NA \\
\hline Delotte et al. (2015) (31) & 15 & $\geq 70(72)$ & No & 11 & 97 & 20 & $0(30)$ & PCI (survival) \\
\hline Beckert et al. (2015) (32) & 29 & $\geq 70(73)$ & Yes (14-69) & 20 & 69 & 21 & $3(90)$ & $\begin{array}{l}\text { Age } \geq 70 \text { years, cardiac and } \\
\text { pulmonary comorbidities } \\
\text { (major morbidity) }\end{array}$ \\
\hline Cascales-Campos et al. (2016) (33) & 85 & $\geq 75$ (77) & No & 12 & 97 & 14.1 & $3.5(30)$ & $\begin{array}{l}\text { DM, albumin, diaphragmatic } \\
\text { resection, blood transfusion } \\
\text { (major morbidity) }\end{array}$ \\
\hline Kitai et al. (2016) (34) & 14 & $\geq 70(75)$ & Yes (38-69) & 32 & 78.5 & 21.4 & $14.3(30)$ & None \\
\hline Current study & 54 & $\geq 65(70)$ & Yes $(60-64)$ & 14 & 77.7 & 11 & $5.5(30)$ & $\begin{array}{l}\mathrm{MM}, \mathrm{CC}, \mathrm{CRC} \text { and sarcoma, } \\
\text { Charlson } \geq 2 \text { (survival) }\end{array}$ \\
\hline
\end{tabular}

CC: Completeness of cytoreduction; CRC: colorectal cancer; DM: diabetes mellitus; MM: major morbidity; NA: not applicable; NR: not reported; SIRS: systemic inflammatory response syndrome. ${ }^{*} \mathrm{CC}$ reported as R0-2. 
Most importantly, we demonstrate that suffering a major surgical complication in this relatively frail population is a dismal event that casts its effect on long-term survival. Tabrizian et al. (11) and Votanopoulos et al. (22) made a similar conclusion regarding their elderly populations that those who are candidates for an uncomplicated surgery, and achieve at least a microscopic cytoreduction $(\mathrm{CCO} / 1)$ should be selected for CRS and HIPEC to provide an optimal outcome.

A recent systematic review (25) summarized the outcomes of 10 reports addressing CRS and HIPEC for the elderly between 2008-2016 $(11,22,26-33)$ in addition to one recent study (34). Our population resembles those reported in the literature in regards to the perioperative demographics, disease-specific characteristics, and surgical outcomes. Many of these reports applied regression analysis to identify the predictors of various outcomes, namely the occurrence of major complications and survival. These studies, including ours, show that CRS and HIPEC in the elderly is feasible with acceptable postoperative morbidity and mortality rates. Moreover, it appears that the pre-existing comorbidities, complicated procedures, and certain primary histologies are common poor prognosticators of both outcomes. One study suggested age as a predictor of worse survival, but that was when the elderly ( $\geq 70$ years) were compared to controls (14-69 years) (32). Our analysis is the first to demonstrate that PCI is not an independent prognostic factor in the elderly, and that its influence on survival ceases in the face of a complete cytoreduction. Thus, supporting the argument that this population can still experience a longer survival with aggressive treatments. Ihemelandu et al. made similar conclusions in their patient population with appendiceal carcinomatosis where $\mathrm{CC} 0 / 1$ overrode $\mathrm{PCI}$ as a prognostic factor in the final survival predictive model (35). The concept that complete cytoreduction is the main determinant of survival regardless of the PCI score was previously suggested, taking into careful consideration the histogenesis of the primary tumor, and the involvement of crucial anatomical sites (36). Studies addressing CRS and HIPEC in the elderly, including the present one, are summarized in Table IV.

We evaluated other factors that might be associated with higher morbidity or mortality such as liver and spleen involvement, neither of which had a prognostic value on the overall survival in our patients. In general, undergoing liver resection for hepatic metastases was not shown to inflict an increase in postoperative complications $(37,38)$, whereas some investigators reported that splenectomy is a risk factor for increased morbidities (39). It is worth mentioning that in our population, splenectomy was not performed unless splenic involvement was evident, and that the majority of the hepatectomies were partial in the context of surface seeding of the liver. Only three patients had parenchymal liver involvement for which an anatomical resection was indicated. Due to the small number of cases, a proper statistical analysis could not be conducted in this regard.

In addition to the relatively small sample size, we recognize that our study is retrospective in nature, which carries inherent shortcomings especially during data collection. For instance, the Eastern Cooperative Oncology Group status was not reported in our patients' charts, and preoperative albumin was only available for half of the population. Therefore, our analysis and conclusions were limited to the variables that were properly reported and collected.

\section{Conclusion}

CRS and HIPEC are feasible and should not be withheld for the elderly. Achievement of $\mathrm{CC} 0 / 1$ is crucial for improved survival in this population despite advanced age where patient selection is key to provide an optimal outcome.

\section{Conflicts of Interests}

The Authors have no financial disclosures nor conflicts of interest to report.

\section{References}

1 Glehen O, Gilly FN, Boutitie F, Bereder JM, Quenet F, Sideris L, Mansvelt B, Lorimier G, Msika S, Elias D; French Surgical Association: Toward curative treatment of peritoneal carcinomatosis from nonovarian origin by cytoreductive surgery combined with perioperative intraperitoneal chemotherapy: a multi-institutional study of 1,290 patients. Cancer 116(24): 5608-5618, 2010.

2 Chua TC, Moran BJ, Sugarbaker PH, Levine EA, Glehen O, Gilly FN, Baratti D, Deraco M, Elias D, Sardi A, Liauw W, Yan TD, Barrios P, Gomez Portilla A, de Hingh IH, Ceelen WP, Pelz JO, Piso P, Gonzalez-Moreno S and Van Der Speeten K and Morris DL: Early- and long-term outcome data of patients with pseudomyxoma peritonei from appendiceal origin treated by a strategy of cytoreductive surgery and hyperthermic intraperitoneal chemotherapy. J Clin Oncol 30(20): 2449-2456, 2012.

3 Chua TC, Yan TD, Saxena A and Morris DL: Should the treatment of peritoneal carcinomatosis by cytoreductive surgery and hyperthermic intraperitoneal chemotherapy still be regarded as a highly morbid procedure?: a systematic review of morbidity and mortality. Ann Surg 249(6): 900-907, 2009.

4 Glehen O, Kwiatkowski F, Sugarbaker PH, Elias D, Levine EA, De Simone M, Barone R, Yonemura Y, Cavaliere F, Quenet F, Gutman M, Tentes AA, Lorimier G, Bernard JL, Bereder JM, Porcheron J, Gomez-Portilla A and Shen P, Deraco M and Rat P: Cytoreductive surgery combined with perioperative intraperitoneal chemotherapy for the management of peritoneal carcinomatosis from colorectal cancer: a multi-institutional study. J Clin Oncol 22(16): 3284-3292, 2004.

5 Verwaal VJ, Bruin S, Boot H, van Slooten G and van Tinteren $\mathrm{H}$ : 8-Year follow-up of randomized trial: cytoreduction and hyperthermic intraperitoneal chemotherapy versus systemic chemotherapy in patients with peritoneal carcinomatosis of colorectal cancer. Ann Surg Oncol 15(9): 2426-2432, 2008. 
6 World Health Organization, Health statistics and information systems. WHO's Programme on Ageing and Life-course 2016 [Available from: http://www.who.int/healthinfo/survey/ ageingdefnolder/en].

7 World Health Organization. World Report on Ageing and Health (Luxembourg), 2015.

8 Duron JJ, Duron E, Dugue T, Pujol J, Muscari F, Collet D, Pessaux P and Hay JM: Risk factors for mortality in major digestive surgery in the elderly: a multicenter prospective study. Ann Surg 254(2): 375-382, 2011.

9 Jacquet P and Sugarbaker PH: Clinical research methodologies in diagnosis and staging of patients with peritoneal carcinomatosis. Cancer Treat Res 82: 359-374, 1996.

10 Elias D, Faron M, Iuga BS, Honore C, Dumont F, Bourgain JL, Dartigues P, Ducreux M and Goere D: Prognostic similarities and differences in optimally resected liver metastases and peritoneal metastases from colorectal cancers. Ann Surg 261(1): 157-163, 2015.

11 Tabrizian P, Jibara G, Shrager B, Franssen B, Yang MJ, Sarpel U, Hiotis S and Labow D: Outcomes for cytoreductive surgery and hyperthermic intraperitoneal chemotherapy in the elderly. Surg Oncol 22(3): 184-189, 2013.

12 Polanczyk CA, Marcantonio E, Goldman L, Rohde LE, Orav J, Mangione CM and Lee TH: Impact of age on perioperative complications and length of stay in patients undergoing noncardiac surgery. Ann Intern Med 134(8): 637-643, 2001.

13 McQuellon RP, Russell GB, Shen P, Stewart JHt, Saunders W and Levine EA: Survival and health outcomes after cytoreductive surgery with intraperitoneal hyperthermic chemotherapy for disseminated peritoneal cancer of appendiceal origin. Ann Surg Oncol 15(1): 125-133, 2008.

14 Kwakman R, Schrama AM, van Olmen JP, Otten RH, de Langede Klerk ES, de Cuba EM, Kazemier G and Te Velde EA: Clinicopathological parameters in patient selection for cytoreductive surgery and hyperthermic intraperitoneal chemotherapy for colorectal cancer metastases: a meta-analysis. Ann Surg 263(6): 1102-1111, 2016.

15 Rey-Ferro M and Castano R, Orozco O, Serna A and Moreno A: Nutritional and immunologic evaluation of patients with gastric cancer before and after surgery. Nutrition 13(10): 878-881, 1997.

16 Sungurtekin H, Sungurtekin U, Balci C, Zencir M and Erdem E: The influence of nutritional status on complications after major intraabdominal surgery. J Am Coll Nutr 23(3): 227-232, 2004.

17 Kuzu MA, Terzioglu H, Genc V, Erkek AB, Ozban M, Sonyurek $\mathrm{P}$, Elhan $\mathrm{AH}$ and Torun $\mathrm{N}$ : Preoperative nutritional risk assessment in predicting postoperative outcome in patients undergoing major surgery. World J Surg 30(3): 378-390, 2006.

18 Schiesser M, Kirchhoff P, Muller MK, Schafer M and Clavien PA: The correlation of nutrition risk index, nutrition risk score, and bioimpedance analysis with postoperative complications in patients undergoing gastrointestinal surgery. Surgery 145(5): 519-526, 2009.

19 Correia MI, Caiaffa WT, da Silva AL and Waitzberg DL: Risk factors for malnutrition in patients undergoing gastroenterological and hernia surgery: an analysis of 374 patients. Nutr Hosp 16(2): 59-64, 2001.

20 Saraiva MD, Karnakis T, Gil-Junior LA, Oliveira JC, Suemoto CK and Jacob-Filho W: Functional status is a predictor of postoperative complications after cancer surgery in the very old. Ann Surg Oncol 24(5): 1159-1164, 2017.
21 Gibbs J, Cull W, Henderson W, Daley J, Hur K and Khuri SF: Preoperative serum albumin level as a predictor of operative mortality and morbidity: results from the National VA Surgical Risk Study. Arch Surg 134(1): 36-42, 1999.

22 Votanopoulos KI, Newman NA, Russell G, Ihemelandu C, Shen P, Stewart JH and Levine EA: Outcomes of cytoreductive surgery (CRS) with hyperthermic intraperitoneal chemotherapy (HIPEC) in patients older than 70 years; survival benefit at considerable morbidity and mortality. Ann Surg Oncol 20(11): 3497-3503, 2013.

23 Shen P, Levine EA, Hall J, Case D, Russell G, Fleming R, McQuellon R, Geisinger KR and Loggie BW: Factors predicting survival after intraperitoneal hyperthermic chemotherapy with mitomycin $\mathrm{C}$ after cytoreductive surgery for patients with peritoneal carcinomatosis. Arch Surg 138(1): 26-33, 2003.

24 Levine EA, Stewart JHt, Russell GB, Geisinger KR, Loggie BL and Shen P: Cytoreductive surgery and intraperitoneal hyperthermic chemotherapy for peritoneal surface malignancy: experience with 501 procedures. J Am Coll Surg 204(5): 943953, discussion 953-945, 2007.

25 Lopez-Lopez V, Cascales-Campos PA, Schneider MA, Gil J, Gil E, Gomez-Hidalgo NR and Parrilla P: Cytoreductive surgery and hyperthermic intraperitoneal chemotherapy (HIPEC) in elderly patients. A systematic literature review. Surg Oncol 25(4): 378384, 2016.

26 Muller H, Hahn M, Weller L and Simsa J: Strategies to reduce perioperative morbidity in cytoreductive surgery. Hepatogastroenterology 55(86-87): 1523-1529, 2008.

27 Macri A, Saladino E, Trimarchi G, Bartolo V, Rossitto M, Cannao A, Rizzo A and Famulari C: Cytoreductive surgery plus hyperthermic intraperitoneal chemotherapy in elderly patients. In Vivo 25(4): 687-690, 2011.

28 Klaver YL, Chua TC, de Hingh IH and Morris DL: Outcomes of elderly patients undergoing cytoreductive surgery and perioperative intraperitoneal chemotherapy for colorectal cancer peritoneal carcinomatosis. J Surg Oncol 105(2): 113$118,2012$.

29 Spiliotis JD, Halkia E, Boumis VA, Vassiliadou DT, Pagoulatou A and Efstathiou E: Cytoreductive surgery and HIPEC for peritoneal carcinomatosis in the elderly. Int J Surg Oncol 2014: 987475, 2014.

30 Cascales-Campos P and Gil J, Gil E, Feliciangeli E, Lopez V, Gonzalez AG, Ruiz-Pardo $J$, Nieto $A$ and Parrilla $P$ : Cytoreduction and HIPEC after neoadjuvant chemotherapy in stage IIIC-IV ovarian cancer. Critical analysis in elderly patients. Eur J Obstet Gynecol Reprod Biol 179: 88-93, 2014.

31 Delotte J, Arias T, Guerin O, Boulahssass R, Bereder I, Bongain A, Benchimol D and Bereder JM: Hyperthermic intraperitoneal chemotherapy for the treatment of recurrent ovarian cancer in elderly women. Acta Obstet Gynecol Scand 94(4): 435-439, 2015.

32 Beckert S, Struller F, Horvath P, Falcke A, Konigsrainer A and Konigsrainer I: Overall morbidity but not mortality is increased in elderly patients following cytoreductive surgery and HIPEC: Langenbecks Arch Surg 400(6): 693-698, 2015.

33 Cascales-Campos PA and Lopez-Lopez V, Munoz-Casares FC, Feliciangeli E, Torres Melero J, Barrios P, Morales R, Ramos I, Ortega G, Camps B, Gonzalez-Bayon L, Bretcha-Boix P, FarreAlegre J, Gonzalez-Moreno S and Gil J: Morbidity and mortality outcomes after cytoreductive surgery and hyperthermic 
intraperitoneal chemotherapy in patients aged 75 years and over: Spanish group of peritoneal cancer surgery (GECOP) multicenter study. Surg Oncol 25(2): 111-116, 2016.

34 Kitai T, Yamanaka K, Miyauchi Y and Kawashima M: Indications for cytoreductive surgery and hyperthermic intraperitoneal chemotherapy in elderly patients with peritoneal malignancy. Int J Clin Oncol 22(3): 519-525, 2017.

35 Ihemelandu C, Fernandez S and Sugarbaker PH: A Prognostic model for predicting overall survival in patients with peritoneal surface malignancy of an appendiceal origin treated with cytoreductive surgery and hyperthermic intraperitoneal chemotherapy. Ann Surg Oncol 24(8): 2266-2272, 2017.

36 Sugarbaker PH: Management of peritoneal-surface malignancy: the surgeon's role. Langenbecks Arch Surg 384(6): 576-587, 1999.

37 Blackham AU, Russell GB, Stewart JHt, Votanopoulos K, Levine EA and Shen P: Metastatic colorectal cancer: survival comparison of hepatic resection versus cytoreductive surgery and hyperthermic intraperitoneal chemotherapy. Ann Surg Oncol 21(8): 2667-2674, 2014
38 Berger Y, Aycart S, Tabrizian P, Agmon Y, Mandeli J, Heskel M, Hiotis S, Sarpel U and Labow DM: Cytoreductive surgery and hyperthermic intraperitoneal chemotherapy in patients with liver involvement. J Surg Oncol 113(4): 432-437, 2016.

39 Dagbert F, Thievenaz R, Decullier E, Bakrin N, Cotte E, Rousset P, Vaudoyer D, Passot G and Glehen O: Splenectomy increases postoperative complications following cytoreductive surgery and hyperthermic intraperitoneal chemotherapy. Ann Surg Oncol 23(6): 1980-1985, 2016.
Received September 17, 2017

Revised October 24, 2017

Accepted October 31, 2017 